\title{
Self-Assembly Hydrosoluble Coronenes: A Rich Source of Supramolecular Turn-On Fluorogenic Sensing Materials in Aqueous Media
}

\author{
Daisy C. Romero, Patricia Calvo-Gredilla, José García-Calvo, Alberto Diez-Varga, José Vicente Cuevas, \\ Andrea Revilla-Cuesta, Natalia Busto, Irene Abajo, Gabriel Aullón, and Tomás Torroba*
}

Cite This: Org. Lett. 2021, 23, 8727-8732

Read Online

ACCESS 1

Џlll Metrics \& More

回 Article Recommendations

Supporting Information

ABSTRACT: Water-soluble coronenes, that form nanoparticles by self-association, work as new fluorescent materials by complexation with cucurbit[7] uril, as well as selective turn-on fluorogenic sensors for nitroaromatic explosives with remarkable selectivity, by using only water as solvent.

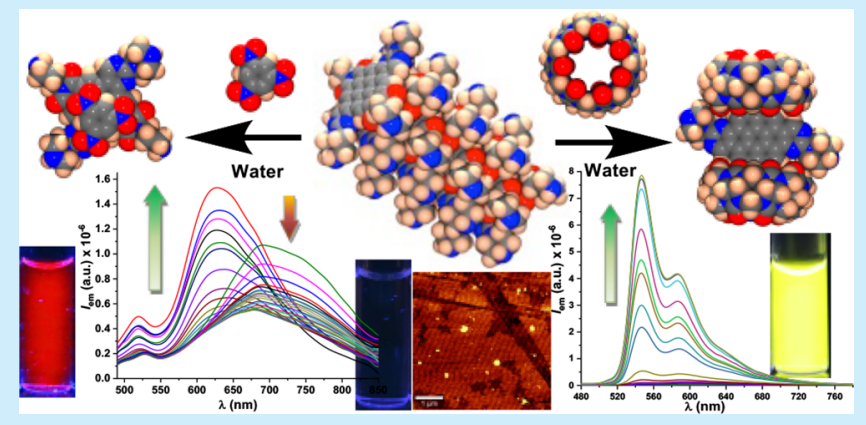

elf-assembling of organic dyes is a rich source of $\checkmark$ nanomaterials for practical applications. ${ }^{1}$ Aggregation of perylenediimides has been deeply studied and these studies constitute a paradigm in organic nanoaggregation. ${ }^{2-5}$ The closely related coronenediimide derivatives have been studied from a structural point of view ${ }^{6-9}$ or in the preparation of aromatic acceptors for solar cells and high-end electronics. ${ }^{10,11}$ Simpler coronenediimides have been used for the preparation of discotic liquid crystals ${ }^{12}$ or water-soluble dendrimers. ${ }^{13}$ However, the excellent characteristics for $\pi-\pi$ stacking or selfassembling make coronenediimides the best choice for molecular recognition studies. We are interested in the preparation of sensing devices for the detection of explosives or toxins in water or vapor. ${ }^{14-16}$ To prepare useful new fluorescent nanomaterials, we have designed an easy route to coronenediimide derivatives having an extended aromatic core surrounded by a hydrophilic periphery, suitable for applications as sensing materials. In this paper, we want to introduce their synthesis and self-assembling characteristics in comparison to related hemicoronene- or perylenediimides. Their unique applications as discrete nanoparticles to supramolecular turn-on fluorescent recognition and sensing of nitroaromatic explosives in water will be presented.

Our synthesis started by the Suzuki reaction of the dibromoperylenediimide 1 with two equivalents of a $N$-Boc protected piperazinyl-pyrimidine boronic ester $\mathbf{2}$ in conditions used for related Suzuki reactions (Figure 1). ${ }^{15,17}$ The bissubstituted, four $N$-Boc protected derivative 3 ( $85 \%$ yield) was obtained after workup of the reaction. Irradiation of 3 in dichoromethane (DCM) under visible light (halogen lamp,
$50 \mathrm{~W}, 4 \mathrm{~cm}$ distance) and air for $7 \mathrm{~h}$ gave the $\mathrm{N}$-Boc protected coronene 4 ( $89 \%$ yield). Traces of an unexpected intermediate of cyclization were also detected. The monocyclized intermediate product $5(76 \%)$ was subsequently obtained as the main product under a shorter irradiation time $(3 \mathrm{~h}) . \mathrm{N}$-Boc deprotection of all compounds by treatment with trifluoroacetic acid (TFA) in DCM for 20 min quantitatively gave the unprotected compounds 6,7 , and 8 , bearing four secondary amine groups on the periphery (Figure 1). Extended hemicoronediimides from monosubstituted perylenediimides have shown interest as semiconducting materials. ${ }^{18-20}$

After study of the physicochemical characteristics of the obtained compounds, we realized that the $N$-Boc protected compounds 3, 4, and 5 were bright fluorescent compounds, soluble in common organic solvents, that showed high quantum yields $\left(0.3-0.6\right.$ in $\mathrm{DCM}$ or $\left.\mathrm{CHCl}_{3}\right)$ and lifetimes similar to the starting material $\mathbf{1}(3-10 \mathrm{~ns}$ ) (Figures S20, S24, and S29). However, the unprotected compounds 6, 7, and 8 were almost non fluorescent compounds, soluble in water but almost insoluble in most organic solvents (Figures S35, S54, and S95). As an exception, 6 initially gave a nonfluorescent solution in water, but the water solution became brightly fluorescent after $24 \mathrm{~h}$. The kinetic study showed the

Received: September 20, 2021

Published: November 9, 2021 


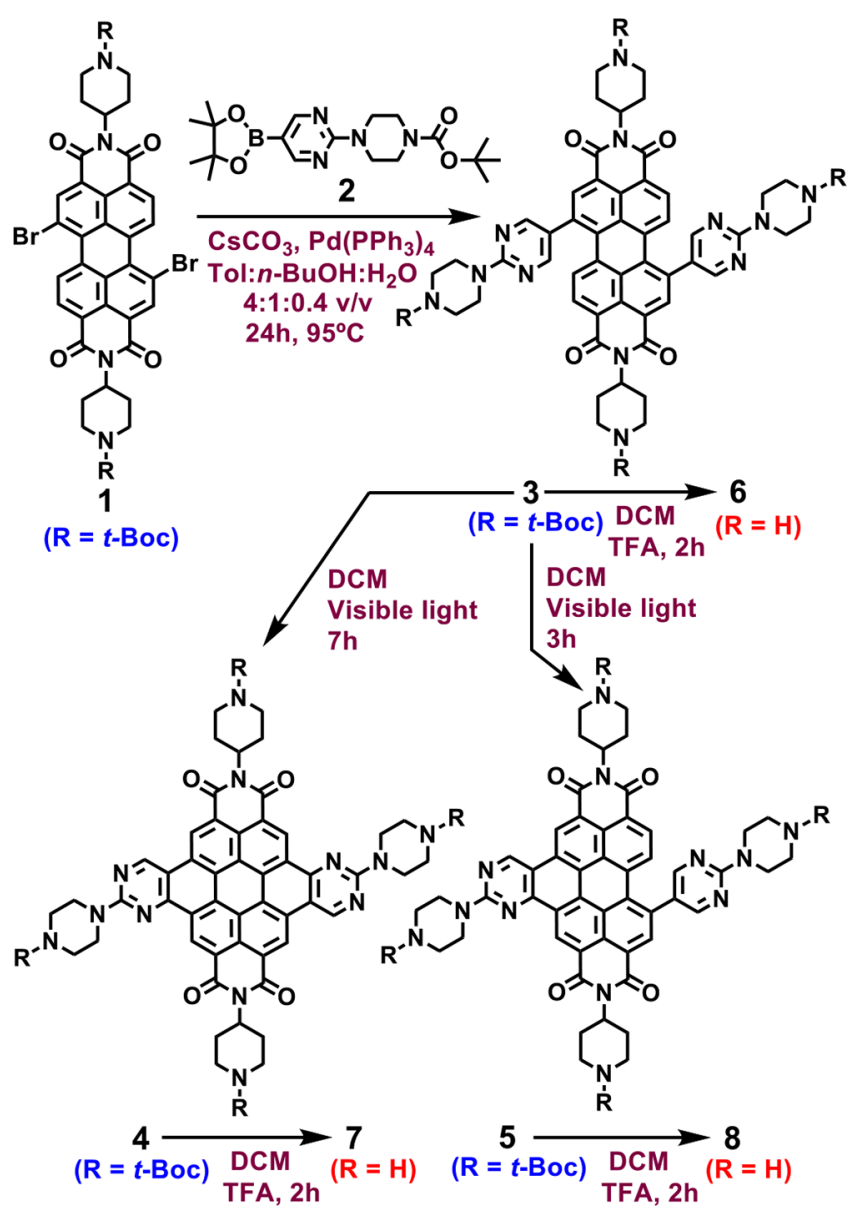

Figure 1. Synthesis of hemicoronene- and coronenediimides.

appearance and continuous growth of a fluorescent band at $502 \mathrm{~nm}$ and a shoulder at $520 \mathrm{~nm}$ after dissolving 6 in water (Figure S38). Then 6, 7 and 8 showed the presence of stable spherical nanoparticles in AFM by deposition of $2 \mu \mathrm{L}$ of aqueous solutions of samples on mica sheets and evaporation of water (tapping mode, force constant $2.8 \mathrm{~N} \mathrm{~m}^{-1}$, room temperature, scan rate 1-2 lines per second) (Figure 2). Because of the large ability of these compounds to selfassociate in water, NMR spectra were not sufficiently informative, especially for 7; therefore, we prepared a derivative of 7 with long hydrophilic tails that prevented selfassociation, 9 (Figure 2), which permitted a full characterization by spectroscopy, confirming the structures. The watersoluble nanoparticles from 6,7 , and 8 , were also characterized by DLS (Figures S40-S44, S59-S60, and S98-S101).

Low molecular weight organic nanoparticles in water constitute an excellent material for studies of aggregation/ disaggregation linked to fluorescence variations on the way to new supramolecular sensing devices. Therefore, we studied in deep disaggregation mechanisms based on molecular recognition. The piperidine/piperazine groups on the periphery of the compounds are expected to be good guests for host-guest chemistry of cucurbiturils in water. ${ }^{21,22}$ Cucurbiturils have been used for the preparation of supramolecular luminescent sensors $^{23}$ or for enhancing fluorescence of perylenediimides in water. $^{24}$ Therefore, we performed several tests by adding aqueous solutions of cucurbit[n]urils, $\mathrm{CB}[5], \mathrm{CB}[6], \mathrm{CB}[7]$, and $\mathrm{CB}[8]$, in $1: 1,1: 5,1: 10$, and 1:20 dye/cucurbituril molar proportions to $10 \mu \mathrm{M}$ aqueous solutions of 6,7 , and 8 . Except
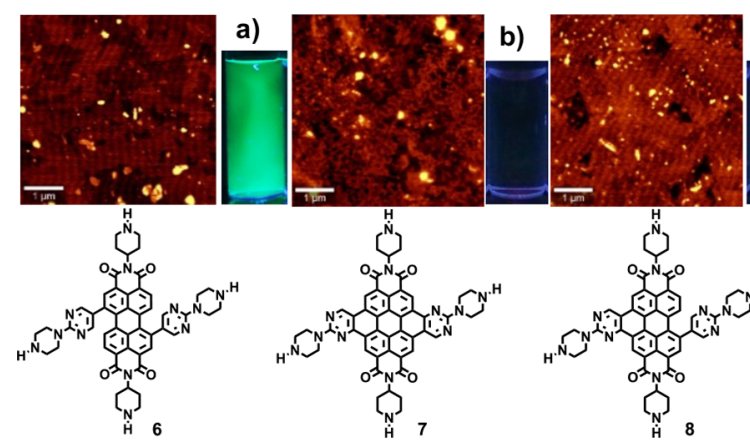

c)

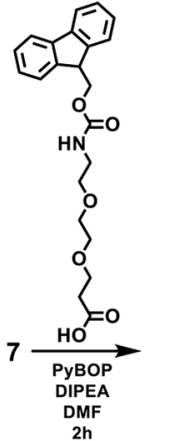

DMF
$2 \mathrm{~h}$

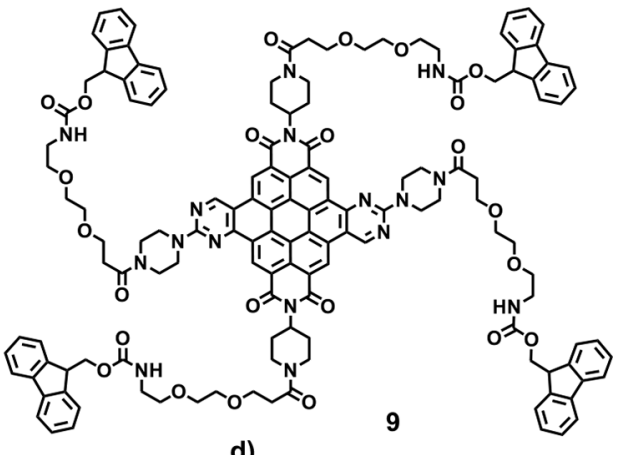

Figure 2. AFM images of samples deposited on mica sheets from water solutions $0.1 \mu \mathrm{g} / \mathrm{mL}$ : (a) 6 (b) 7 (c) 8 . (d) Derivatization of coronene 7 to 9 .

for 6, compounds 7 and 8 showed a neat increase of fluorescence in the presence of $\mathrm{CB}[7]$ (Figures S45, S61, and S102). Then we performed fluorescent titrations of $10 \mu \mathrm{M}$ solutions of 7 and 8 in water by adding increasing amounts of concentrated solutions of $\mathrm{CB}[7]$ (Figure 3).

The fluorescent titration curves and titration profiles of 10 $\mu \mathrm{M}$ solutions of 7 and 8 in water, with $\mathrm{CB}[7]$, showed asymptotic increases of fluorescence when a large excess of $\mathrm{CB}$ [7] was added (Figure 3). Additional UV-vis absorption titrations are shown in Figures S62 and S109. In this way, 7 and 8 solutions in water became brightly fluorescent in the presence of a large excess of $\mathrm{CB}[7]$, expanding the narrow range of fluorescent hemicoronene/coronenediimides in water solutions. $\mathrm{CB}[7]$ is expected to host small molecular guests; $^{25,26}$ therefore, in this series, the complexation with $\mathrm{CB}[7]$ should happen by the piperidine/piperazine groups, ${ }^{26}$ giving rise to disaggregation to form individual complexes in solution. The disaggregation effect worked in the opposite way in the case of 6 , where the presence of excess $\mathrm{CB}[5], \mathrm{CB}[6]$, or $\mathrm{CB}[7]$ in $10 \mu \mathrm{M}$ water solutions of 6 hindered the development of fluorescence (Figures S45 and S46). The type of complex formed between $\mathrm{CB}[7]$ and 7 or $\mathbf{8}$ was studied by Job's plot experiments and isothermal titration calorimetry (ITC) measurements, but the results were inconclusive. Instead, accurate mass spectrometry measurements afforded high resolution $\mathrm{m} / z$ peaks of the lowest terms in the series of expected complexes, 7@CB[7] ( $m / z$ 2040.7227) and 8@ $\mathrm{CB}[7](\mathrm{m} / z 2043.7303)$, a low resolution peak of the complex 7@2CB[7] $(m / z 3208.1)$, and self-associated compounds such as $[7]_{2}(\mathrm{~m} / z 1757.6),[7]_{3}\left(\mathrm{~m} / z\right.$ 2634.9), and $[7]_{4}(\mathrm{~m} / z$ 3515.9) (Figures S51-S53 and S92-S94). With these results, we looked for new applications of the aggregation/ disaggregation mechanism that could afford light on the mechanism as well as new sound applications in sensing. In the 


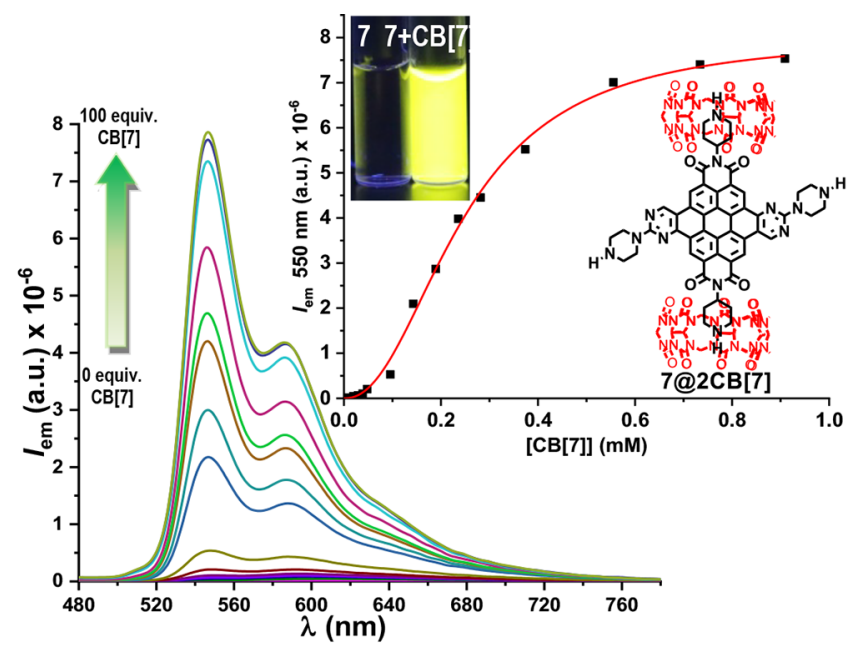

increasing amounts of TNT (Figure 4). The fluorescent titration curves and ratiometric titration profiles of $10 \mu \mathrm{M}$

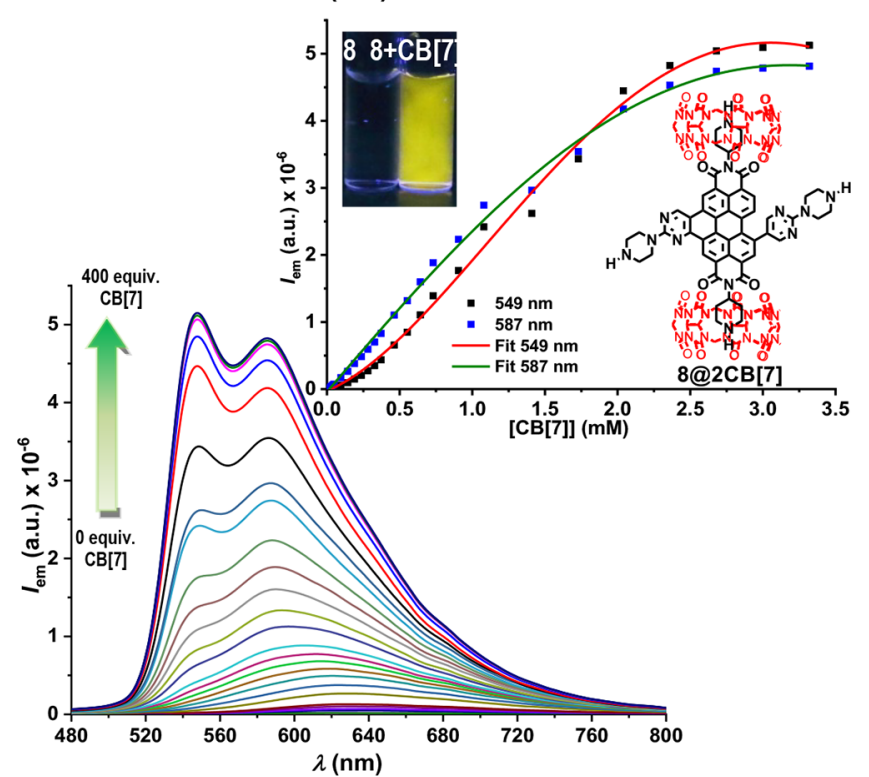

Figure 3. Fluorescent titration curves and titration profiles of $10 \mu \mathrm{M}$ solutions of 7 and 8 in water with increasing amounts of $\mathrm{CB}[7], 0$ to 100 equiv $\mathrm{CB}[7]$ for titration of 7 and 0 to 400 equiv $\mathrm{CB}[7]$ for titration of 8. Inset: solution samples of $\mathbf{7}$ and $\mathbf{8}$ under UV light, 365 $\mathrm{nm}$, before and after titrations with $\mathrm{CB}[7]$.

initial tests, 7 or $\mathbf{8}$ were not sensitive to common cations, anions, acids or oxidants in water, but 7 showed a dramatic appearance of red fluorescence in the presence of 1,3,5trinitrobenzene (TNB), a common explosive. Consequently, the study was extended to trinitrotoluene (TNT), a commonly used explosive that is usually detected by quenching of fluorescence from suitable fluorophores ${ }^{27-32}$ with very few exceptions. $^{33-35}$ For this reason, TNT lacks a turn-on fluorogenic method for its detection in water with practical use. Taking into account the large number of sunken warfare materials still existing in the oceans from the Word Wars I and $\mathrm{II}^{36}$ the design of new fluorogenic sensing materials for the detection of TNB/TNT in water is worthy of study. Titration of a $10 \mu \mathrm{M}$ solution of 7 in water with TNB, 0 to $6 \mathrm{mg} / \mathrm{mL}$ TNB, showed a decrease in a $690 \mathrm{~nm}$ far red band and an increase of a $632 \mathrm{~nm}$ red band in fluorescence with the addition of increasing amounts of TNB. Analogously, titration of a $10 \mu \mathrm{M}$ solution of 7 in water with TNT, 0 to $1.77 \mathrm{mg} / \mathrm{mL}$ TNT, also showed a decrease in the $700 \mathrm{~nm}$ band and an increase of a $595 \mathrm{~nm}$ band in fluorescence with the addition of
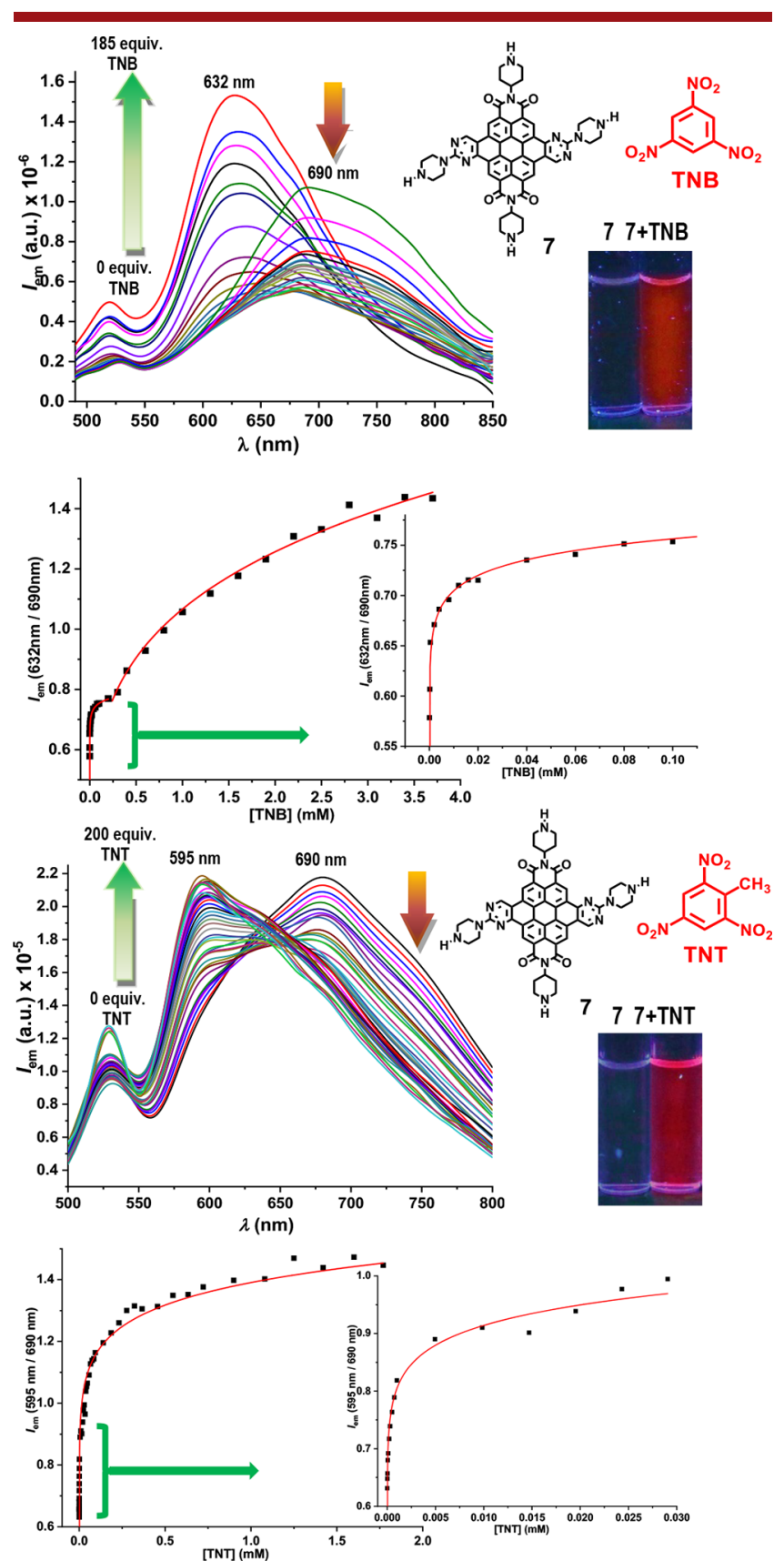

Figure 4. Fluorescent titration curves and ratiometric titration profiles of $10 \mu \mathrm{M}$ solutions in water of 7 with increasing amounts of TNB and TNT, with expansions of the first parts of the titration plots. Insets: water solution samples of 7 under UV light, $365 \mathrm{~nm}$, before and after titration with TNB/TNT.

solutions in water of 7 with increasing amounts of TNB and TNT are shown in Figure 4. In addition, the lifetime decay changed from an initial value of 4.95 to $4.62 \mathrm{~ns}$ after addition of TNB or TNT to solutions of 7 in water, but there were no significant changes in the absorbance values under the same conditions. The evolution of changes seems to be correlated to selective disaggregation processes, which produced ratiometric changes in fluorescence, with increases of the final red fluorescence from almost 0 to $2 / 3 \%$. From the titration plots 
in every case, we calculated the LODs by IUPAC-consistent methods. ${ }^{37}$ From the standard deviation equation $[\mathrm{LOD}=3.3$ $\times \mathrm{SD} / \mathrm{s}], \mathrm{LOD}=3.3 \times 0.00583 / 0.894=0.02 \mu \mathrm{M}$ for TNB and $\mathrm{LOD}=3.3 \times 1.056 / 59=0.06 \mu \mathrm{M}$ for $\mathrm{TNT}$, comparable to LODs from previous reports, ${ }^{33,34}$ but in this case with the unprecedented feature of using only water in the titration. We also calculated the LODs within the values measured (different than 0 ) by adjusting the initial values to a mean square linear regression and using the $\mathrm{R}$ program (SI page S114), which can be considered as a good approach to the limits of quantification of the system. By this way, measured values were $\mathrm{LOQ}=0.046 \mu \mathrm{M}$ for $\mathrm{TNB}$ and $\mathrm{LOQ}=0.21 \mu \mathrm{M}$ for TNT. With a solubility of $100 \mathrm{mg} / \mathrm{L}$ for TNT (0.44 mM) (SI, page $\mathrm{S} 115)$ in pure water or seawater at $20{ }^{\circ} \mathrm{C}$, the LOQs found are suitable for the detection of traces of TNT in environmental aquatic samples by a turn-on fluorescence mechanism. The system can also be applied to TNB, which is roughly as three-times more soluble in water/seawater than TNT (SI, page S115). Indeed, 7 was not sensitive to the presence of common cations, anions, or usual interferents found in water (Figures S72-S88); therefore, its presence did not interfere the TNB/TNT detection.

Attempts of determining binding constants from the fluorescence titration experiments gave the best fitting from the titration of 7 and TNT for a $1: 2$ model (supramolecular.org), being $K_{1}=(2.3 \pm 1.3) \times 10^{5} \mathrm{M}^{-1}$ and $K_{2}=$ $(3.4 \pm 1.0) \times 10^{3} \mathrm{M}^{-1}$ the apparent formation constants of the $7 / \mathrm{TNT}(1: 1)$ and $7 /(\mathrm{TNT})_{2}(1: 2)$ complexes, respectively. Because of the large uncertainties, they have only a qualitative value, indicating that multiple association accounted for the disaggregation of 7 in the presence of TNT. Aggregation of 7 was studied by ITC measurements (Figure S89). The binding isotherm was fitted by a dimer dissociation model (NanoAnalyze Software, TA Instruments). We obtained thermodynamic parameters, $K_{\mathrm{agg}}=(1.39 \pm 0.4) \times 10^{4} \mathrm{M}^{-1}, \Delta H=-66$ $\pm 2 \mathrm{~kJ} \mathrm{~mol}^{-1}$, and $\Delta S=-142 \pm 9 \mathrm{~J} \mathrm{~mol}^{-1} \mathrm{~K}^{-1}$, that agreed with the aggregation process.

To understand the interactions, we performed theoretical DFT calculations (SI, p S76) of the complexes between two self-aggregated 7 , and then 7 with two $\mathrm{CB}[7]$ or one TNB (Figure 5).

The results showed that dimer $[7]_{2}$ had stabilization energy of $-52.24 \mathrm{kcal} / \mathrm{mol}$ with respect to the two isolated molecules (Figure 5a,b). The most stable calculated structure for the complex 7@2CB[7] was 7@2(apical)CB[7] (Figure 5c), followed by 7@2(equatorial) $\mathrm{CB}[7]$ (Figure 5d), less stable by $25.16 \mathrm{kcal} / \mathrm{mol}$. The interaction of $7 \cdot \mathrm{CB}[7]$ was theoretically modeled, finding that for $1: 1$ complexes the entry through the apical position had a calculated complexation energy $[\mathrm{CCE}]=-44.59 \mathrm{kcal} / \mathrm{mol}$, while the interaction through the equatorial position displayed $[\mathrm{CCE}]=-39.71$ $\mathrm{kcal} / \mathrm{mol}$. The entry of a second $\mathrm{CB}[7]$ in complexes $1: 2 \mathrm{had}$ $[\mathrm{CCE}]=-34.26 \mathrm{kcal} / \mathrm{mol}$ for 7@2(apical) $\mathrm{CB}[7]$ and [CCE] $=-28.36 \mathrm{kcal} / \mathrm{mol}$ for 7@2(equatorial) $\mathrm{CB}[7]$, indicating an apical preferred interaction. The $[7 \cdot \mathrm{TNB}]$ complex was modeled by calculating the complexation energy using the counterpoise correction (SI, p S66) (Figure 5e,f), giving $[\mathrm{CCE}]=-18.17 \mathrm{kcal} / \mathrm{mol}$.

In conclusion, we have prepared a new series of perylene-, hemicoronene-, and coronene diimides that were soluble in water, giving nanoparticles by self-association, which in turn worked as new fluorescent materials by self-aggregation or complexation with cucurbit[7] uril, as well as selective turn-on

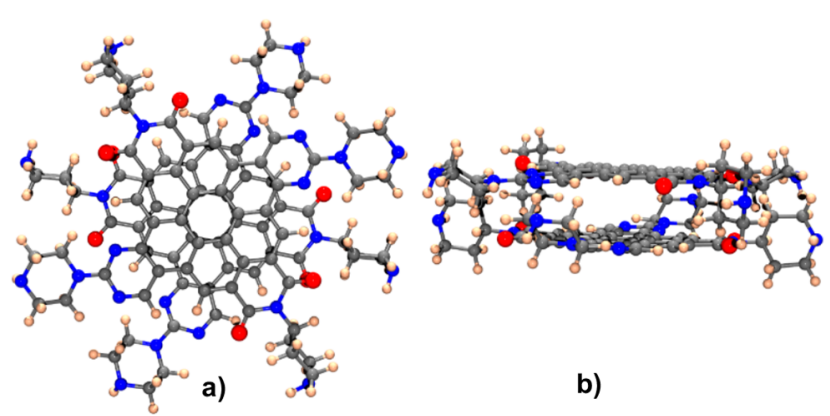

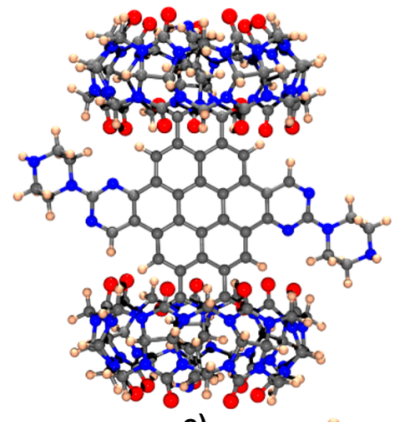
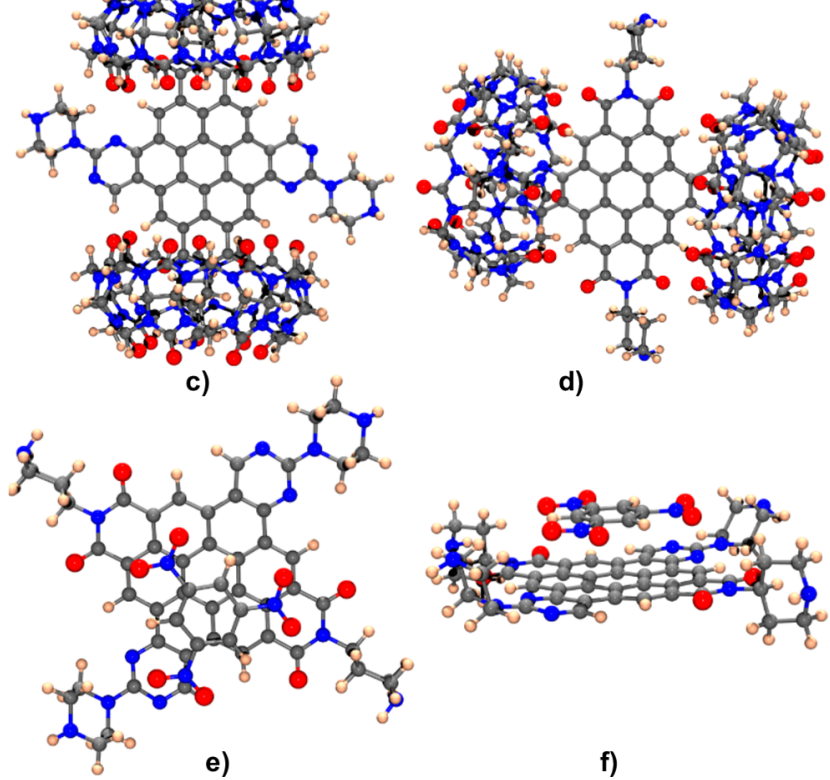

d)

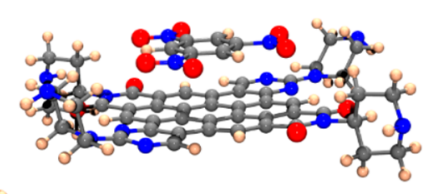

f)
Figure 5. (a) Calculated structure of dimer $[7]_{2}$ seen from a parallel plane to the structure and (b) from a perpendicular plane. (c) Calculated structure of complex 7@2(apical)CB[7], relative energy (0 $\mathrm{kcal} / \mathrm{mol}$ ), and (d)7@2(equatorial) $\mathrm{CB}[7]$, relative energy (25.16 $\mathrm{kcal} / \mathrm{mol}$ ). (e) Calculated structure of complex $7 \cdot \mathrm{TNB}$ seen from a parallel plane to the aromatic structure or (f) from a perpendicular plane.

fluorogenic sensors for explosive trinitroaromatic compounds, with remarkable selectivity, by using only water as solvent.

\section{ASSOCIATED CONTENT}

\section{Supporting Information}

The Supporting Information is available free of charge at https://pubs.acs.org/doi/10.1021/acs.orglett.1c03175.

Compound structures (XYZ)

Synthetic procedures, complete characterization of all compounds, additional experiments, theoretical calculations (PDF)

\section{AUTHOR INFORMATION}

\section{Corresponding Author}

Tomás Torroba - Department of Chemistry, Faculty of Science, University of Burgos, 09001 Burgos, Spain; Institut de Química Tèrica i Computacional (IQTCUB), Universitat de Barcelona, 08028 Barcelona, Spain; ○ orcid.org/0000-0002-5018-4173; Email: ttorroba@ ubu.es 


\section{Authors}

Daisy C. Romero - Department of Chemistry, Faculty of Science, University of Burgos, 09001 Burgos, Spain; Institut de Química Tèorica i Computacional (IQTCUB), Universitat de Barcelona, 08028 Barcelona, Spain

Patricia Calvo-Gredilla - Department of Chemistry, Faculty of Science, University of Burgos, 09001 Burgos, Spain; Institut de Química Tèrica i Computacional (IQTCUB), Universitat de Barcelona, 08028 Barcelona, Spain

José García-Calvo - Department of Chemistry, Faculty of Science, University of Burgos, 09001 Burgos, Spain; Institut de Química Tè̀rica i Computacional (IQTCUB), Universitat de Barcelona, 08028 Barcelona, Spain

Alberto Diez-Varga - Department of Chemistry, Faculty of Science, University of Burgos, 09001 Burgos, Spain; Institut de Química Tèrica i Computacional (IQTCUB), Universitat de Barcelona, 08028 Barcelona, Spain

José Vicente Cuevas - Department of Chemistry, Faculty of Science, University of Burgos, 09001 Burgos, Spain; Institut de Química Tèrica i Computacional (IQTCUB), Universitat de Barcelona, 08028 Barcelona, Spain; (1) orcid.org/0000-0002-2421-1529

Andrea Revilla-Cuesta - Department of Chemistry, Faculty of Science, University of Burgos, 09001 Burgos, Spain; Institut de Química Tèrica i Computacional (IQTCUB), Universitat de Barcelona, 08028 Barcelona, Spain

Natalia Busto - Department of Chemistry, Faculty of Science, University of Burgos, 09001 Burgos, Spain; Institut de Química Tèrica i Computacional (IQTCUB), Universitat de Barcelona, 08028 Barcelona, Spain; 이잉.org/00000001-9637-1209

Irene Abajo - Department of Chemistry, Faculty of Science, University of Burgos, 09001 Burgos, Spain; Institut de Química Tèrica i Computacional (IQTCUB), Universitat de Barcelona, 08028 Barcelona, Spain

Gabriel Aullón - Institut de Química Tèrica i Computacional (IQTCUB), Universitat de Barcelona, 08028 Barcelona, Spain

Complete contact information is available at:

https://pubs.acs.org/10.1021/acs.orglett.1c03175

\section{Notes}

The authors declare no competing financial interest.

\section{ACKNOWLEDGMENTS}

We acknowledge NATO Science for Peace and Security Programme (SPS G5536), Ministerio de Ciencia, Innovación y Universidades-FEDER (PID2019-111215RB-100 and RTI2018-102040-B-100), Junta de Castilla y León, Consejería de Educación y Cultura y Fondo Social Europeo (BU263P18) and "la Caixa" Foundation (LCF/PR/PR12/11070003) for financial support. A.R.C. thanks Secretaría General de Universidades (FPU18/03225). We thank M. Pilar Castroviejo, from PCT, UBU, for assistance in AFM studies and Javier Gutierrez, from LTI, UVA, for assistance in DLS studies.

\section{REFERENCES}

(1) Gao, M.; Tang, B. Z. Fluorescent Sensors Based on AggregationInduced Emission: Recent Advances and Perspectives. ACS Sens 2017, 2, 1382-1399.
(2) Würthner, F. Perylene bisimide dyes as versatile building blocks for functional supramolecular architectures. Chem. Commun. 2004, 1564-1579.

(3) Würthner, F.; Saha-Möller, C. R.; Fimmel, B.; Ogi, S.; Leowanawat, P.; Schmidt, D. Perylene Bisimide Dye Assemblies as Archetype Functional Supramolecular Materials. Chem. Rev. 2016, 116, 962-1052.

(4) Ji, C.; Cheng, W.; Yuan, Q.; Müllen, K.; Yin, M. From Dyestuff Chemistry to Cancer Theranostics: The Rise of Rylenecarboximides. Acc. Chem. Res. 2019, 52, 2266-2277.

(5) Liu, C.; Zhang, S.; Li, J.; Wei, J.; Müllen, K.; Yin, M. A WaterSoluble, NIR-Absorbing Quaterrylenediimide Chromophore for Photoacoustic Imaging and Efficient Photothermal Cancer Therapy. Angew. Chem., Int. Ed. 2019, 58, 1638-1642.

(6) Endres, A. H.; Schaffroth, M.; Paulus, F.; Reiss, H.; Wadepohl, H.; Rominger, F.; Krämer, R.; Bunz, U. H. F. Coronene-Containing N-Heteroarenes: 13 Rings in a Row. J. Am. Chem. Soc. 2016, 138, $1792-1795$

(7) Liu, B.; Böckmann, M.; Jiang, W.; Doltsinis, N. L.; Wang, Z. Perylene Diimide-Embedded Double [8]Helicenes. J. Am. Chem. Soc. 2020, 142 (15), 7092-7099.

(8) Schuster, N. J.; Sánchez, R. H.; Bukharina, D.; Kotov, N. A.; Berova, N.; Ng, F.; Steigerwald, M. L.; Nuckolls, C. A Helicene Nanoribbon with Greatly Amplified Chirality. J. Am. Chem. Soc. 2018, 140, 6235-6239.

(9) Peurifoy, S. R.; Castro, E.; Liu, F.; Zhu, X.-Y.; Ng, F.; Jockusch, S.; Steigerwald, M. L.; Echegoyen, L.; Nuckolls, C.; Sisto, T. J. ThreeDimensional Graphene Nanostructures. J. Am. Chem. Soc. 2018, 140, 9341-9345.

(10) Zhang, G.; Zhao, J.; Chow, P. C. Y.; Jiang, K.; Zhang, J.; Zhu, Z.; Zhang, J.; Huang, F.; Yan, H. Nonfullerene Acceptor Molecules for Bulk Heterojunction Organic Solar Cells. Chem. Rev. 2018, 118, 3447-3507.

(11) Zhu, W.; Alzola, J. M.; Aldrich, T. J.; Kohlstedt, K. L.; Zheng, D.; Hartnett, P. E.; Eastham, N. D.; Huang, W.; Wang, G.; Young, R. M.; Schatz, G. C.; Wasielewski, M. R.; Facchetti, A.; Melkonyan, F. S.; Marks, T. J. Fluorine Tuning of Morphology, Energy Loss, and Carrier Dynamics in Perylenediimide Polymer Solar Cells. ACS Energy Lett. 2019, 4, 2695-2702.

(12) Zhao, K.-Q.; An, L.-L.; Zhang, X.-B.; Yu, W.-H.; Hu, P.; Wang, B.-Q.; Xu, J.; Zeng, Q.-D.; Monobe, H.; Shimizu, Y.; Heinrich, B.; Donnio, B. Highly Segregated Lamello-Columnar Mesophase Organizations and Fast Charge Carrier Mobility in New Discotic Donor-Acceptor Triads. Chem. - Eur. J. 2015, 21, 10379-10390.

(13) Schmidt, C. D.; Lang, N.; Jux, N.; Hirsch, A. A Facile Route to Water-Soluble Coronenes and Benzo[ghi]perylenes. Chem. - Eur. J. 2011, 17, 5289-5299.

(14) García-Calvo, J.; Robson, J. A.; Torroba, T.; Wilton-Ely, J. D. E. T. Synthesis and Application of Ruthenium(II) Alkenyl Complexes with Perylene Fluorophores for the Detection of Toxic Vapours and Gases. Chem. - Eur. J. 2019, 25, 14214-14222.

(15) García-Calvo, J.; Calvo-Gredilla, P.; Ibáñez-Llorente, M.; Romero, D. C.; Cuevas, J. V.; García-Herbosa, G.; Avella, M.; Torroba, T. Surface functionalized silica nanoparticles for the off-on fluorogenic detection of an improvised explosive, TATP, in a vapour flow. J. Mater. Chem. A 2018, 6, 4416-4423.

(16) Díaz de Greñu, B.; García-Calvo, J.; Cuevas, J.; García-Herbosa, G.; García, B.; Busto, N.; Ibeas, S.; Torroba, T.; Torroba, B.; Herrera, A.; Pons, S. Chemical speciation of $\mathrm{MeHg}^{+}$and $\mathrm{Hg}^{2+}$ in aqueous solution and HEK cells nuclei by means of DNA interacting fluorogenic probes. Chem. Sci. 2015, 6, 3757-3764.

(17) García-Calvo, V.; Cuevas, J. V.; Barbero, H.; Ferrero, S.; Álvarez, C. M.; González, J. A.; Díaz de Greñu, B.; García-Calvo, J.; Torroba, T. Synthesis of a Tetracorannulene-perylenediimide That Acts as a Selective Receptor for C60 over C70. Org. Lett. 2019, 21, 5803-580.

(18) Nagarajan, K.; Mallia, A. R.; Muraleedharan, K.; Hariharan, M. Enhanced intersystem crossing in core-twisted aromatics. Chem. Sci. 2017, 8, 1776-1782. 
(19) Ziffer, M. E.; Jo, S. B.; Zhong, H.; Ye, L.; Liu, H.; Lin, F.; Zhang, J.; Li, X.; Ade, H. W.; Jen, A. K.-Y.; Ginger, D. S. Long-Lived, Non-Geminate, Radiative Recombination of Photogenerated Charges in a Polymer/Small-Molecule Acceptor Photovoltaic Blend. J. Am. Chem. Soc. 2018, 140, 9996-10008.

(20) Wu, M.; Yi, J.-P.; Chen, L.; He, G.; Chen, F.; Sfeir, M. Y.; Xia, J. Novel Star-Shaped Helical Perylene Diimide Electron Acceptors for Efficient Additive-Free Nonfullerene Organic Solar Cells. ACS Appl. Mater. Interfaces 2018, 10, 27894-27901.

(21) Pazos, E.; Novo, P.; Peinador, C.; Kaifer, A. E.; García, M. D. Cucurbit[8]uril ( $\mathrm{CB}[8])$-Based Supramolecular Switches. Angew. Chem., Int. Ed. 2019, 58, 403-416.

(22) Liu, J.; Lan, Y.; Yu, Z.; Tan, C. S. Y.; Parker, R. M.; Abell, C.; Scherman, O. A. Cucurbit[n] uril-Based Microcapsules Self-Assembled within Microfluidic Droplets: A Versatile Approach for Supramolecular Architectures and Materials. Acc. Chem. Res. 2017, 50, 208-217.

(23) Mako, T. L.; Racicot, J. M.; Levine, M. Supramolecular Luminescent Sensors. Chem. Rev. 2019, 119, 322-477.

(24) Biedermann, F.; Elmalem, E.; Ghosh, I.; Nau, W. M.; Scherman, O. A. Strongly Fluorescent, Switchable Perylene Bis(diimide) Host-Guest Complexes with Cucurbit[8]uril In Water. Angew. Chem., Int. Ed. 2012, 51, 7739-7743.

(25) Thomas, S. S.; Tang, H.; Bohne, C. Noninnocent Role of Na+ Ions in the Binding of the N-Phenyl-2-naphthylammonium Cation as a Ditopic Guest with Cucurbit[7]uril. J. Am. Chem. Soc. 2019, 141, 9645-9654.

(26) Masson, E.; Ling, X.; Joseph, R.; Kyeremeh-Mensah, L.; Lu, X. Cucurbituril chemistry: a tale of supramolecular success. RSC Adv. 2012, 2, 1213-1247.

(27) Maka, V. K.; Mukhopadhyay, A.; Savitha, G.; Moorthy, J. N. Fluorescent 2D metal-organic framework nanosheets (MONs): design, synthesis and sensing of explosive nitroaromatic compounds (NACs). Nanoscale 2018, 10, 22389-22399.

(28) Goudappagouda; Dongre, S. D.; Das, T.; Babu, S. S. Dual mode selective detection and differentiation of TNT from other nitroaromatic compounds. J. Mater. Chem. A 2020, 8, 10767-10771.

(29) Abuzalat, O.; Wong, D.; Park, S. S.; Kim, S. Highly selective and sensitive fluorescent zeolitic imidazole frameworks sensor for nitroaromatic explosive detection. Nanoscale 2020, 12, 13523-13530.

(30) Sun, Y.; Wu, Y.; Yu, C.; Zhang, L.; Song, G.; Yao, Z. SelfAssembly of Nanoscale Induced Excimers of 12-Pyren-1-yldodecanoic Acid for TNT Detection. ACS Appl. Nano Mater. 2019, 2, 34533458.

(31) Delente, J. M.; Umadevi, D.; Shanmugaraju, S.; Kotova, O.; Watson, G. W.; Gunnlaugsson, T. Aggregation induced emission (AIE) active 4-amino-1,8-naphthalimide-Tröger's base for the selective sensing of chemical explosives in competitive aqueous media. Chem. Commun. 2020, 56, 2562-2565.

(32) Wan, W.-M.; Tian, D.; Jing, Y.-N.; Zhang, X.-Y.; Wu, W.; Ren, H.; Bao, H.-L. NBN-Doped Conjugated Polycyclic Aromatic Hydrocarbons as an AIEgen Class for Extremely Sensitive Detection of Explosives. Angew. Chem., Int. Ed. 2018, 57, 15510-15516.

(33) Kim, S.; Kim, H.; Qiao, T.; Cha, C.; Lee, S. K.; Lee, K.; Ro, H. J.; Kim, Y.; Lee, W.; Lee, H. Fluorescence Enhancement from NitroCompound-Sensitive Bacteria within Spherical Hydrogel Scaffolds. ACS Appl. Mater. Interfaces 2019, 11, 14354-14361.

(34) Zhang, Z.; Chen, S.; Shi, R.; Ji, J.; Wang, D.; Jin, S.; Han, T.; Zhou, C.; Shu, Q. A single molecular fluorescent probe for selective and sensitive detection of nitroaromatic explosives: A new strategy for the mask-free discrimination of TNT and TNP within same sample. Talanta 2017, 166, 228-233.

(35) Tripathi, N.; Kumar, R.; Singh, P.; Kumar, S. Ratiometric fluorescence "Turn On" probe for fast and selective detection of TNT in solution, solid and vapour. Sens. Actuators, B 2017, 246, 10011010. and references therein.

(36) Maser, E.; Strehse, J. S. Don't Blast": blast-in-place (BiP) operations of dumped World War munitions in the oceans significantly increase hazards to the environment and the human seafood consumer. Arch. Toxicol. 2020, 94, 1941-1953.

(37) Allegrini, F.; Olivieri, A. C. IUPAC-Consistent Approach to the Limit of Detection in Partial Least-Squares Calibration. Anal. Chem. 2014, 86, 7858-7866. and references therein. 